\title{
Cost of asthma in the Asia-Pacific region
}

\author{
C.K.W. Lai*, Y-Y. Kim, S-H. Kuo", M. Spencer ${ }^{+}$, A.E. Williams ${ }^{+}$on behalf of the \\ Asthma Insights and Reality in Asia Pacific Steering Committee
}

ABSTRACT: The substantial morbidity caused by asthma suggests that the disease is associated with a large economic burden. The current study analysed the burden of asthma in eight countries in the Asia-Pacific region.

Responses to questions regarding resource use from a survey of people with asthma were analysed. Unit costs were obtained for each resource use element. Individual patient costs were estimated and means calculated for each country. A multivariate model was developed to identify potential predictors of resource use.

Annual per-patient direct costs ranged from US\$108 for Malaysia to US\$1,010 for Hong Kong. When productivity costs were included, total per-patient societal costs ranged from US\$184 in Vietnam to US\$1,189 in Hong Kong. Urgent care costs were responsible for $18-90 \%$ of total perpatient direct costs. Overall, total per-patient direct costs were equivalent to $13 \%$ of per capita gross domestic product and $300 \%$ of per capita healthcare spending. Extremes of age, greater severity of asthma, and poorer general health status were predictive of high cost.

The per-patient cost of asthma in these countries is high, particularly when seen in the context of overall per-patient healthcare spending. Strategies to improve asthma control are likely to not only improve patient outcomes, but also to decrease societal costs.

\section{KEYWORDS: Asia Pacific, asthma, asthma control, Far East, healthcare costs}

$\mathbf{T}$ he prevalence of asthma has increased substantially during the past 40 yrs [1-3]. Although the reasons for this increase are unknown, both lifestyle and environmental factors have been suggested. While the increase has been noted worldwide, there is substantial variation in prevalence rates of asthma, with up to 15fold differences between countries [4]. Therefore, country- and region-specific data are essential.

Epidemiological surveys have determined that asthma is a substantial problem in the AsiaPacific region [4-6]. The control of asthma in the Asia-Pacific region has also been shown to fall short of goals set by current guidelines [7, 8]. In the Asthma Insights and Reality in Asia-Pacific (AIRIAP) study, $>40 \%$ of patients with asthma reported having been hospitalised, having attended an emergency dept, or having made unscheduled emergency visits to other healthcare facilities in the past year [7].

Because of the challenge imposed by the frequency and severity of asthma, the economic burden of the disease has also increased in recent years $[3,9,10]$. In the US, the cost of asthma was estimated to be US\$12.7 billion annually in 1998 [10]. In Germany, this amounted to $€ 2.74$ billion in 1999 [11]. The economic burden of asthma is particularly substantial in developing countries where healthcare resources are limited and there is difficulty in implementing new healthcare initiatives [12].

There are few data on the costs of asthma in developing countries, including the Asia-Pacific region. This article aims to describe the perpatient costs of asthma (direct, indirect and societal) in the Asia-Pacific region based on the data of the AIRIAP study.

\section{METHODS}

The AIRIAP survey was conducted from September to December 2000 in urban centres of eight areas in the Asia-Pacific region: China (Beijing, Shanghai, Guangzhou), Hong Kong, Korea (Seoul), Malaysia (Klang Valley, Penang, Johor Baru, Ipoh), the Philippines (Metro Manila), Singapore, Taiwan (Taipei) and Vietnam (Hanoi, Ho Chi Minh City). The AIRIAP survey was designed to determine the burden of asthma and the level of unmet needs for the disease. Although the survey was not specifically designed to collect cost data, questions relating to resource use were included, allowing a retrospective comparison of treatment costs across the region.

\section{Participants}

The selection of participants for AIRIAP has been described in depth previously [7]. In brief, sampling was performed via face-to-face interviews

\section{AFFILIATIONS}

*Dept of Medicine and Therapeutics, The Chinese University of Hong Kong, Hong Kong.

\#Dept of Internal Medicine, Seoul National University College of Medicine, Seoul, Korea.

"Depts of Laboratory Medicine and Internal Medicine, College of

Medicine National Taiwan University, Taipei, Taiwan.

${ }^{+}$GlaxoSmithKline R\&D Ltd,

Greenford, UK.

CORRESPONDENCE

C.K.W. Lai

Room 1403

Takshing House

20 Des Voeux Road Central

Hong Kong

Fax: 85225222188

E-mail: keilai@netvigator.com
European Respiratory Review Print ISSN 0905-9180 Online ISSN 1600-0617 
conducted either by random street interception, random door-to-door recruitment or telephone. Not all recruitment methods were used in all areas. The screening population was drawn from 108,360 households with recruitment by each of the three methods at various times of the day and on different days of the week to ensure that a representative cross-section was included. An adult representative of each household was asked whether a household member had ever been diagnosed with asthma. If the household member was said to have experienced an asthma attack or asthma symptom in the last 12 months or to be receiving asthma medication, the respondent was considered eligible for a subsequent face-to-face interview. The study was designed to have 400 respondents in each of the eight areas.

Interviews of 45-60-min duration were conducted in the respondents' homes. The questionnaire was based on the American Thoracic Society questionnaire [13], with supplementary questions on healthcare utilisation and limitation of activity. If required, translators experienced in the use of health surveys translated the English version of the questionnaire into other languages.

\section{Per-patient cost calculations}

Responses to survey questions relating to resource use were reviewed and analysed. Additional assumptions were made (in consultation with clinical experts in the region) to allow an analysis of resource use.

Per-patient costs were separated into direct (healthcare) and indirect (productivity), and also aggregated into total societal costs. Per-patient costs were analysed by country as total costs using a societal perspective. In addition, costs as a proportion of gross domestic product (GDP) per capita (year 2000) and healthcare spending per capita (year 2000) were calculated. With the exception of Taiwan, where the values came from local government sources, per capita GDP and healthcare spending values were derived from the World Bank. Unit costs were obtained from local sources in each individual area (e.g. standard government or insurance sources, hospital billing data or consultation with local experts) and reviewed by the AIRIAP steering committee. Costs are expressed in US\$ (year 2000 market exchange rate) and are presented as means and SE. Total mean per-patient costs are presented across the sample as a simple average with no weighting for country population as an illustrative summary figure and should not be interpreted as the mean per-patient costs across the region.

\section{Direct costs}

Direct costs included the costs of physician contacts and drug costs (costs for herbal and Chinese medicines were excluded from the analysis). Physician contacts were costed according to whether they were routine or urgent care. Routine visits were costed as the cost of a general practitioner (GP) visit if the respondent indicated that the specialty of the physician they saw most often for their asthma was a general or family practice physician. Otherwise visits were costed at double the rate for a GP to account for a higher cost of specialist visits. Separate costs were obtained for urgent care visits. Inpatient days were costed at the per diem rate for a hospital stay. If a respondent indicated regular use of a drug, an average annual cost was applied. Direct costs were estimated as total costs, urgent versus maintenance costs, and drug versus non-drug costs.

\section{Indirect and societal costs}

Indirect costs were determined using the human capital approach. Only respondents aged $\geqslant 16 \mathrm{yrs}$, and who were working, were included as part of the national workforce and included in the analysis of indirect costs. Since no wage rate for respondents was available, the "total household monthly income" from the questionnaire was used as a proxy. The mid point for each income band indicated by each respondent was assumed to be his or her monthly income. The monthly incomes were converted to daily incomes adjusting for local variations in the average number of days worked per yr in each country. Lost productivity was calculated as the number of days of work missed per yr multiplied by the average daily salary. Societal costs per patient were calculated as the sum of indirect and direct costs.

\section{Multivariate analysis}

The relationship between postulated predictors of resource use and the cost of asthma were investigated using a saturated mixed effects analysis of covariance model, with the dependent variable as the natural log of per capita GDP adjusted costs [14], with a random effect for area and fixed effects for age, sex, severity of asthma, patient reported control status (dichotomised to "complete" and "well" (controlled) versus "somewhat", "poor" and "not at all" (not controlled)), and general health status. Analysis on the log scale implies a multiplicative model on the natural scale such that the exponential of parameter estimates can be interpreted as independent multiplication factors or ratios (ratio of geometric means).

\section{RESULTS}

\section{Participants}

All 3,207 patients in the AIRIAP survey were included in this analysis. The mean age, proportion of male/female and proportion of smokers in each country are shown in table 1. The mean age of all participants was $31.4 \mathrm{yrs}$, ranging across the areas from 22.8 (the Philippines) to 43.9 (China). In all areas but Hong Kong and Taiwan, the majority of the participants were female. The minority of the participants were smokers varying across the areas from 12.1 (Vietnam) to $23.1 \%$ (Taiwan).

\begin{tabular}{lccc} 
TABLE 1 & Patient demographics & \\
Country & $\begin{array}{c}\text { Mean age } \\
\text { yrs }\end{array}$ & $\begin{array}{c}\text { Females } \\
\%\end{array}$ & $\begin{array}{c}\text { Smokers } \\
\text { (responders) \% }\end{array}$ \\
& & & \\
China & 43.9 & 51.5 & 20.7 \\
Hong Kong & 31.8 & 36.8 & 21.3 \\
Korea & 29.9 & 59.1 & 19.6 \\
Malaysia & 28.7 & 53.0 & 19.1 \\
The Philippines & 22.8 & 53.8 & 21.8 \\
Singapore & 25.2 & 54.8 & 16.3 \\
Taiwan & 32.0 & 46.8 & 23.1 \\
Vietnam & 36.7 & 57.5 & 12.1 \\
Total & 31.4 & 51.6 & 19.1 \\
\hline
\end{tabular}




\begin{tabular}{lcc}
$\begin{array}{l}\text { TABLE 2 } \\
\text { Country }\end{array}$ & $\begin{array}{l}\text { Maintenance care visits by area } \\
\text { GP visits }\end{array}$ & Specialist visits \\
\hline China & 16.39 & 0.94 \\
Hong Kong & 6.48 & 0.78 \\
Korea & 18.81 & 2.72 \\
Malaysia & 10.53 & 1.08 \\
The Philippines & 8.40 & 2.54 \\
Singapore & 5.10 & 0.66 \\
Taiwan & 12.24 & 0.94 \\
Vietnam & 4.64 & 1.03 \\
Total & 10.32 & 1.33 \\
\hline
\end{tabular}

Data are presented as mean number of visits. GP: general practitioner.

\section{Healthcare resource use}

The mean number of maintenance visits per patient per yr to the GP and specialist are shown in table 2. The mean number of GP visits per patient per yr was 10.32. Notably, patients in China, Korea and Taiwan reported a higher than average number of GP visits per patient per yr (16.39, 18.81 and 12.24, respectively) with the mean number visits per patient per yr being lower than average in Vietnam (4.64), Singapore (5.10), the Philippines (8.40) and Hong Kong (6.48). Korea also showed a higher than average number of specialist visits per patient per year (2.72), as did the Philippines (2.54), the mean being 1.33 visits to the specialist per patient per yr. As was the case with GP visits, Singapore and Hong Kong showed a low mean number of visits to a specialist per patient per yr, 0.66 and 0.78 , respectively.

The proportion of patients reporting urgent (unscheduled) resource use (in-patient admission, emergency room (ER) visits and unscheduled physician visits) and the mean annual number of visits per patient are shown in table 3. Overall, nearly one-third $(30 \%)$ of patients reported using urgent physician visit(s) in the past year, with the majority of areas showing a similar level of use. The proportion of patients using urgent physician visits was particularly high in Hong Kong
$(83 \%)$ and low in Vietnam $(6 \%)$. The number of visits also varied greatly from the mean of 1.21 in these two areas: 4.20 (Hong Kong) and 0.10 (Vietnam). The proportion of patients reporting an ER visit in the past year and the mean number of visits was less variable across the areas, with approximately one in five patients reporting an ER visit in the past year, a mean of 0.46 patients per yr. The proportion of patients reporting an ER visit in Korea, however, was low (6\%), with a mean number of visits of 0.09 patients per yr. Patients in Vietnam indicated a higher use of hospitalisations, with $26 \%$ of patients reporting an in-patient stay in the past year compared with a regional mean of $15 \%$. A higher than average proportion of patients in the Philippines $(20 \%)$ also reported in-patients stays. The mean number of in-patient stays per patient per yr (1.94) was notably higher than the average in China (4.55) and Vietnam (4.43), and lower in Hong Kong (0.92) and Singapore (0.41).

\section{Direct per-patient costs}

Direct costs are summarised in table 4 . The mean \pm SE total direct annual cost per patient was US\$320 \pm 15 , ranging from US\$1010 \pm 100 in Hong Kong to US\$108 \pm 13 in Malaysia. On average, the urgent care costs were higher than maintenance costs, as well as for half of the participating areas: Singapore, Hong Kong, Malaysia and China (table 4). Overall, urgent care costs represented $62 \%$ of total costs, with values ranging from $89 \%$ of costs in Hong Kong to $18 \%$ in the Philippines (fig. 1). Per-patient drug costs represented only $\sim 30 \%$ of total perpatient direct costs (US\$95 versus US $\$ 225$ for drug versus nondrug costs). As a proportion of total direct costs, drug costs were lowest in Hong Kong (9\%) and highest in the Philippines (75\%).

Mean total per-patient direct costs as a proportion of mean per capita healthcare spending and as a proportion of per capita GDP are summarised in table 5. For the entire region, perpatient direct costs represented $13 \%$ of per capita GDP with values ranging from $1 \%$ (Singapore) to $35 \%$ (Vietnam). The per-patient direct costs of asthma exceeded at least one-third of the mean per capita healthcare spending in all countries. The per-patient direct costs of asthma were much higher in

\section{TABLE 3 Urgent care visits by area}

\begin{tabular}{|c|c|c|c|c|c|c|}
\hline \multirow[t]{2}{*}{ Country } & \multicolumn{2}{|c|}{ In-patient stays } & \multicolumn{2}{|c|}{ ER visits } & \multicolumn{2}{|c|}{ Urgent physician visits } \\
\hline & Patients \% & Mean no. days ${ }^{\#}$ & Patients \% & Mean no. visits $\#$ & Patients \% & Mean no. visits ${ }^{\#}$ \\
\hline China & 16 & 4.55 & 32 & 0.89 & 27 & 0.80 \\
\hline Hong Kong & 10 & 0.92 & 18 & 0.35 & 83 & 4.20 \\
\hline Korea & 14 & 2.13 & 6 & 0.09 & 30 & 1.65 \\
\hline Malaysia & 15 & 1.18 & 12 & 0.34 & 22 & 0.90 \\
\hline The Philippines & 20 & 0.76 & 27 & 0.55 & 29 & 0.79 \\
\hline Singapore & 9 & 0.41 & 12 & 0.20 & 23 & 0.52 \\
\hline Taiwan & 12 & 1.20 & 25 & 0.58 & 22 & 0.72 \\
\hline Vietnam & 26 & 4.43 & 22 & 0.71 & 6 & 0.10 \\
\hline Total & 15 & 1.94 & 19 & 0.46 & 30 & 1.21 \\
\hline
\end{tabular}

ER: emergency room. ${ }^{*}$ : per patient per yr. 
TABLE 4 Direct per-patient healthcare costs by area

\begin{tabular}{|c|c|c|c|c|c|c|}
\hline Country & Subjects $n$ & Total cost & \multicolumn{2}{|c|}{ Urgent versus maintenance care } & \multicolumn{2}{|c|}{ Drug versus other } \\
\hline China & 400 & $277 \pm 28$ & $87 \pm 5$ & $190 \pm 27$ & $93 \pm 6$ & $183 \pm 27$ \\
\hline Malaysia & 404 & $108 \pm 13$ & $40 \pm 3$ & $68 \pm 12$ & $13 \pm 1$ & $95 \pm 12$ \\
\hline The Philippines & 400 & $212 \pm 11$ & $173 \pm 9$ & $39 \pm 5$ & $160 \pm 9$ & $52 \pm 5$ \\
\hline Singapore & 400 & $211 \pm 22$ & $88 \pm 6$ & $123 \pm 20$ & $51 \pm 4$ & $160 \pm 21$ \\
\hline Taiwan & 400 & $328 \pm 23$ & $206 \pm 11$ & $121 \pm 19$ & $176 \pm 9$ & $152 \pm 19$ \\
\hline Vietnam & 400 & $141 \pm 12$ & $86 \pm 8$ & $55 \pm 8$ & $78 \pm 8$ & $63 \pm 8$ \\
\hline Total & 3207 & $320 \pm 15$ & $120 \pm 3$ & $199 \pm 14$ & $95 \pm 2$ & $225 \pm 14$ \\
\hline
\end{tabular}

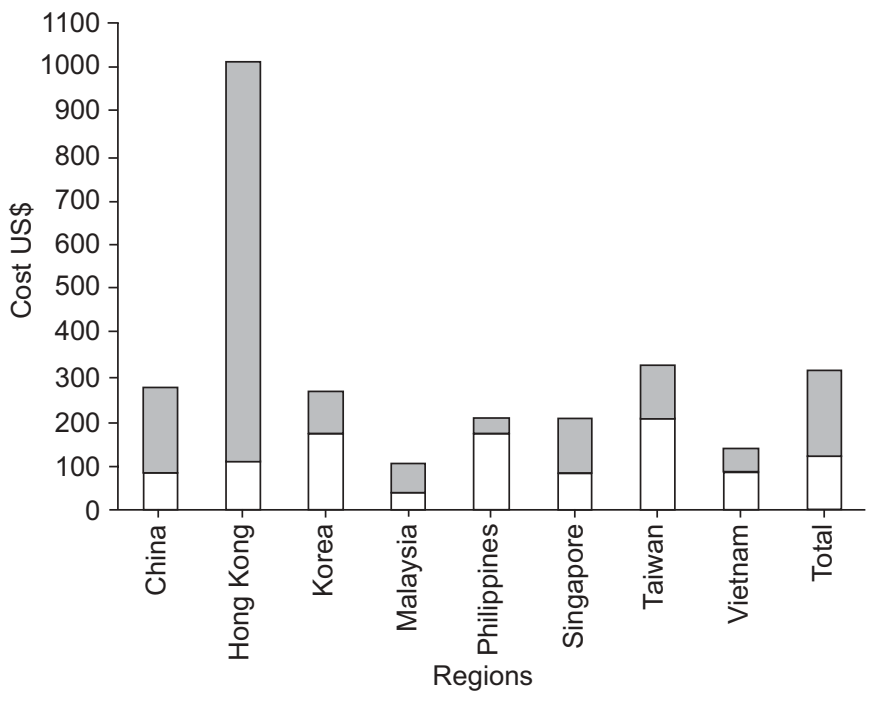

FIGURE 1. Urgent and maintenance care as proportion of per-patient total care costs by area. $\square$ : urgent care costs; $\square$ : maintenance care costs.
Vietnam (829\%), China (691\%) and the Philippines (573\%) than mean per capita healthcare spending.

\section{Per-patient indirect and societal costs}

Overall, mean $\pm \mathrm{SE}$ total per-patient societal costs were US $\$ 435 \pm 17$, ranging from a low of US\$184 \pm 16 in Vietnam to a high of US\$1,189 \pm 105 in Hong Kong (table 6). This represents $16 \%$ of per capita GDP when all countries are pooled. The per capita GDP societal costs of asthma were particularly high in China (39\%), Vietnam (46\%), and the Philippines (28\%).

\section{Determinants of healthcare expenditure}

The multivariate analysis identified several factors that are predictive of increased healthcare expenditures (table 7). Extremes of age ( $<10 \mathrm{yrs}$ and $>60 \mathrm{yrs}$ ), asthma severity and general health status were significantly predictive of higher asthma-related costs. Predicted costs for patients aged 1160 yrs were $35-60 \%$ lower than those for the very young or the very old. Not unexpectedly, there was also a significant and graded relationship between the severity of asthma and the general health status and costs. For example, persistent asthma predicted higher costs compared with intermittent asthma.

TABLE 5 Total per-patient direct costs as a proportion of healthcare dollars and per capita gross domestic product (GDP)

\begin{tabular}{lccc} 
Country & Subjects $\mathbf{n}$ & $\begin{array}{c}\text { Total per-patient direct cost as a } \\
\text { percentage of the per capita GDP \% }\end{array}$ & $\begin{array}{c}\text { Total per-patient dite } \\
\text { percentage of per capita }\end{array}$ \\
\hline China & 400 & 32 & 691 \\
Hong Kong & 402 & 4 & 89 \\
Korea & 401 & 3 & 57 \\
Malaysia & 404 & 3 & 133 \\
The Philippines & 400 & 21 & 573 \\
Singapore & 400 & 1 & 31 \\
Taiwan & 400 & 35 & 53 \\
Vietnam & 400 & 13 & 829 \\
Total & 3207 & & 307
\end{tabular}




\begin{tabular}{lccc} 
TABLE 6 & Total per-patient societal costs by country \\
Country & Subjects n & $\begin{array}{c}\text { Total societal } \\
\text { per-patient cost }\end{array}$ & $\begin{array}{c}\text { Total societal } \\
\text { per-patient cost } \\
\text { as a percentage of } \\
\text { per capita GDP \% }\end{array}$ \\
\hline China & 399 & $336 \pm 32$ & 39 \\
Hong Kong & 402 & $1189 \pm 105)$ & 5 \\
Korea & 401 & $331 \pm 23)$ & 3 \\
Malaysia & 401 & $210 \pm 24)$ & 5 \\
The Philippines & 400 & $277 \pm 15)$ & 28 \\
Singapore & 400 & $450 \pm 40)$ & 2 \\
Taiwan & 396 & $495 \pm 48)$ & 4 \\
Vietnam & 393 & $184 \pm 16)$ & 46 \\
Total & 3192 & $435 \pm 17)$ & 16 \\
\hline
\end{tabular}

Data are presented as mean \pm SE in US $\$$, unless otherwise stated. GDP: gross domestic product.

\begin{tabular}{|c|c|c|}
\hline Parameter & Relative cost ratio & $95 \% \mathrm{Cl}$ \\
\hline \multicolumn{3}{|l|}{ Sex } \\
\hline Male & 1.00 & $0.9-1.11$ \\
\hline Female & 1.00 & \\
\hline \multicolumn{3}{|l|}{ Age yrs } \\
\hline$<5$ & 1.02 & $0.76-1.37$ \\
\hline $5-10$ & 0.83 & $0.64-1.06$ \\
\hline $11-15$ & 0.54 & $0.4-0.72$ \\
\hline $16-20$ & 0.61 & $0.47-0.79$ \\
\hline $21-30$ & 0.54 & $0.42-0.7$ \\
\hline $31-40$ & 0.72 & $0.56-0.93$ \\
\hline $41-50$ & 0.74 & $0.57-0.96$ \\
\hline $51-60$ & 0.73 & $0.55-0.96$ \\
\hline $61-70$ & 0.89 & $0.67-1.17$ \\
\hline$>70$ & 1.00 & \\
\hline \multicolumn{3}{|l|}{ Asthma severity } \\
\hline Severe persistent & 2.51 & $2.08-3.02$ \\
\hline Moderate persistent & 2.36 & $2.01-2.76$ \\
\hline Mild persistent & 1.60 & $1.4-1.84$ \\
\hline Mild intermittent & 1.00 & \\
\hline \multicolumn{3}{|l|}{$\begin{array}{l}\text { Perceived asthma } \\
\text { control }\end{array}$} \\
\hline Uncontrolled & 1.51 & $1.33-1.71$ \\
\hline Controlled & 1.00 & \\
\hline \multicolumn{3}{|l|}{$\begin{array}{l}\text { Self-reported general } \\
\text { health }\end{array}$} \\
\hline Excellent & 0.42 & $0.12-0.42$ \\
\hline Very good & 0.49 & $0.16-0.49$ \\
\hline Good & 0.57 & $0.19-0.57$ \\
\hline Fair & 0.77 & $0.26-0.77$ \\
\hline Poor & 1.18 & $0.38-1.18$ \\
\hline Very poor & 1.00 & \\
\hline
\end{tabular}

Data have been adjusted for country. Cl: confidence interval.
Severe persistent patients had a ratio of 2.51 (range 2.08-3.02) compared with those with intermittent asthma.

Even after correction for asthma severity and general health status, perceived asthma control was highly predictive of cost with an independent effect of raising costs by $>50 \%$. This relationship is investigated further in a univariate fashion in figure 2, which shows that maintenance costs for the two groups do not differ greatly whilst urgent care costs are greatly inflated in the uncontrolled group.

\section{DISCUSSION}

Since there are few data describing the economic burden of asthma in the Asia-Pacific region, the results of this study provide valuable information. This study attempts to apply a common methodology to costing of asthma across the region allowing comparisons between countries. Comparisons are aided by reference to economic indicators for each territory.

A key finding of this study is that asthma takes a tremendous economic toll on this region. In particular, although there is substantial variation between countries, the relative perpatient costs of asthma in this region are extremely high. While the direct and indirect per-patient costs of asthma are lower than those reported for developed countries such as the US and Western Europe [15-17], the economic burden on countries in the Asia-Pacific region is higher in relation to per capita healthcare expenditure or per capita GDP. For example, WEISS et al. [9] reported per-patient costs of $\sim$ US $\$ 750$ for the US (1994). While this represents only a modestly higher dollar amount than that seen in the current study, the amount spent as a percentage of per capita US healthcare spending was only $12 \%$, and only $2 \%$ of US per capita GDP. The burden of asthma (per-patient costs) as a percentage of healthcare costs or per capita GDP was much greater for the AIRIAP countries (i.e. $300 \%$ of per capita healthcare costs and $13 \%$ of per capita GDP overall). Even for the country with the lowest apparent burden (Singapore), medical costs as a percentage of healthcare dollars $(32 \%)$ were almost three-fold higher than that of the US example.

A perhaps more standard technique for accounting for differences in purchasing power across countries would be to use purchasing power parity exchange rates, which adjust

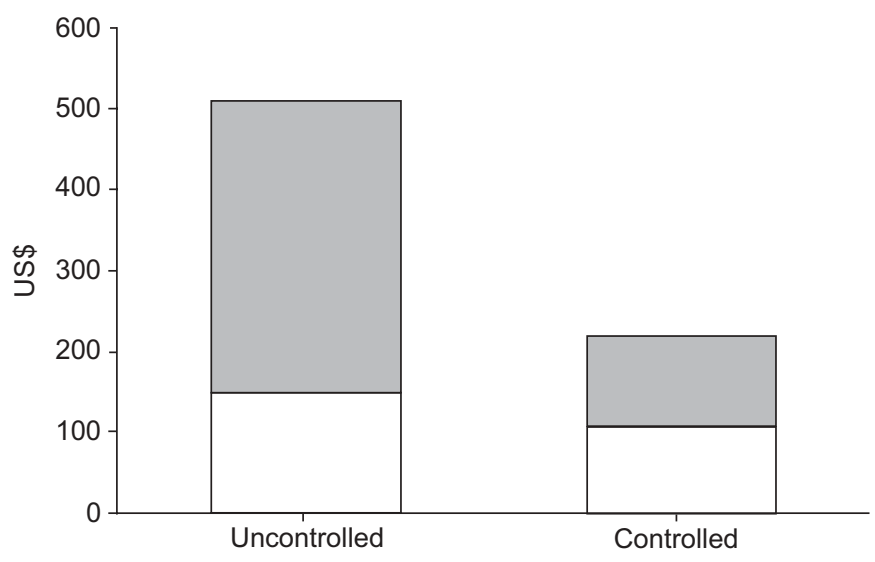

FIGURE 2. Total per-patient costs according to control status. $\square$ : urgent care costs: $\square$ : maintenance costs 
exchange rates to account for the cost of a basket of goods in that country compared with the same basket of goods in the USA. For the countries of interest this would serve to inflate the dollar values when compared with the market exchange rate method applied in this paper. It is, however, not clear how relevant such a method (and the basket of goods chosen) is when used for public or private spending on healthcare in these countries, and hence per capita GDP and healthcare spending have been provided as a reference.

The reason(s) for the substantial differences in GDP-adjusted per-patient costs of asthma between countries are unclear. However, it appears that at least some of the difference is related to differences in disease burden. This is supported by a concordance of days of work lost and the GDP-adjusted costs (data not shown). However, it is also possible that the differences are related to the bias towards urban areas in this study: the countries with the highest estimated GDP-adjusted burdens were those with the small proportion of the population residing in urban areas (i.e. China, Vietnam and the Philippines). Variability in per capita healthcare spending between countries may also reflect differences in healthcare systems and/or governmental policy. The importance of the exclusion of traditional Chinese and herbal medicines should not be underestimated, particularly in China, where nearly half of the respondents were taking some non-conventional medication (no other country had $>3 \%$ taking these medications): these medications incur a cost to society with a dubious benefit to the patient's health. Other limitations of the study include the variable sampling methods used across territories and the reliance on expert opinion for many of the assumptions necessary to allow the original survey responses to be used in the costing exercise and in estimation of some unit costs. However, it is considered that, within the constraints of the original survey, these data provide a useful addition to knowledge of the burden of asthma in the region.

Poor control of asthma is an important factor in the cost of treating the disease [18]. Asthma exacerbations are costly, especially when they require hospital care. A UK survey found that the cost of treating a person who had experienced an asthma attack (£381) was more than three and a half times the cost of treating someone whose asthma was managed without exacerbations $(£ 108)[19,20]$. Patients who require a visit to hospital emergency depts, even without admission, have been shown to incur substantial costs [21].

In this study, the costs for urgent care accounted for $\sim 60 \%$ of total direct costs. This contrasts with the situation in a socialist country, such as Germany, where indirect costs comprised three-quarters of total costs and more than half of the former costs were for the payment of sick benefits [11]. In developing countries, such as those in the Asia-Pacific region, a substantial proportion of the costs associated with asthma are a result of poor control of the disease, leading to urgent healthcare utilisation. This is further supported by multivariate and univariate analyses of cost by control status, suggesting that even after controlling for underlying health status and disease severity, perceived control was strongly related to cost. These data suggest that improvements in treatment strategies have the potential to decrease costs by increasing control and lessening the burden of urgent care. This hypothesis is supported by existing evidence from other regions, which suggest that in addition to poorer clinical outcomes, the underuse of effective asthma therapy has been shown to be associated with increased healthcare expenditures by increasing the requirement for hospitalisation [22]. Improvements in maintenance therapy with either inhaled steroids alone or in combination with an inhaled long-acting $\beta$-agonist have been shown to achieve a well-controlled state in a majority of asthma patients [23]. This well-controlled state would be likely to result in decreases in the need for urgent care visits. That appropriate treatment can lead to cost-saving is demonstrated in a US Medicaid population of 180 asthmatics where the use of inhaled corticosteroids significantly reduced overall costs of care compared with a matched cohort of 233 patients not receiving these drugs [24]. In the year following initiation of the regimen, there was a $24 \%$ overall total monthly saving in the inhaled corticosteroid group.

The results of this study are in general accord with previously published studies. For example, CHAN et al. [25] found that the direct cost of asthma was US\$187 for children and US\$276 for adults in Malaysia. These values are somewhat higher than reported here, but the difference may be related to differences in patient populations because the study by Chan recruited hospitalised patients. Costs for hospitalisation and emergency care accounted for 27 and $44 \%$ of total costs, respectively. In another study conducted in Singapore, the total cost of asthma was US\$238 (direct and indirect) per person with asthma per $\mathrm{yr}$, with direct costs accounting for approximately one-half of total costs [15].

In summary, asthma inflicts a substantial economic burden on healthcare systems in the Asia-Pacific region. Given the high proportion of total costs attributable to urgent care and to lost productivity, and the relationship between control and cost, strategies to improve asthma control may provide advantages not only to the patient but also to society as a whole.

\section{ACKNOWLEDGEMENTS}

The authors would like to thank A. Bhome, India, for comments on earlier drafts and J. Soriano, GlaxoSmithKline.

\section{REFERENCES}

1 Beasley R. The burden of asthma with specific reference to the United States. J Allergy Clin Immunol 2002; 109: Suppl. 5, S482-S489.

2 Cleland J, Thomas M, Price D. Pharmacoeconomics of asthma treatment. Expert Opin Pharmacother 2003; 4: 311-318.

3 Redd SC. Asthma in the United States: burden and current theories. Environ Health Perspect 2002; 110: Suppl. 4, 557-560.

4 The International Study of Asthma and Allergies in Childhood Steering Committee. Worldwide variations in the prevalence of asthma symptoms: the International Study of Asthma and Allergies in Childhood (ISAAC). Eur Respir J 1998; 12: 315-335.

5 Kim YY, Cho SH, Kim WK, et al. Prevalence of childhood asthma based on questionnaires and methacholine bronchial provocation test in Korea. Clin Exp Allergy 1997; 27: 761-768. 
6 Lai CK, Douglass C, Ho SS, et al. Asthma epidemiology in the Far East. Clin Exp Allergy 1996; 26: 5-12.

7 Lai CK, De Guia TS, Kim YY, et al. Asthma control in the Asia-Pacific region: the Asthma Insights and Reality in Asia-Pacific Study. J Allergy Clin Immunol 2003; 111: 263-268.

8 Rabe KF, Adachi M, Lai CK, et al. Worldwide severity and control of asthma in children and adults: the global asthma insights and reality surveys. J Allergy Clin Immunol 2004; 114: 40-47.

9 Weiss KB, Sullivan SD, Lyttle CS. Trends in the cost of illness for asthma in the United States, 1985-1994. J Allergy Clin Immunol 2000; 106: 493-499.

10 Weiss KB, Sullivan SD. The health economics of asthma and rhinitis. I. Assessing the economic impact. J Allergy Clin Immunol 2001; 107: 3-8.

11 Stock S, Redaelli M, Luengen M, Wendland G, Civello D, Lauterbach KW. Asthma: prevalence and cost of illness. Eur Respir J 2005; 25: 47-53.

12 Ait-Khaled N, Enarson D, Bousquet J. Chronic respiratory diseases in developing countries: the burden and strategies for prevention and management. Bull World Health Organ 2001; 79: 971-979.

13 Ferris BG. Epidemiology Standardization Project (American Thoracic Society). Am Rev Respir Dis 1978; 118: $1-120$.

14 Diehr P, Yanez D, Ash A, Hornbrook M, Lin DY. Methods for analyzing health care utilization and costs. Annu Rev Public Health 1999; 20: 125-144.

15 Chew FT, Goh DY, Lee BW. The economic cost of asthma in Singapore. Aust N Z J Med 1999; 29: 228-233.
16 Cisternas MG, Blanc PD, Yen $\mathrm{IH}$, et al. A comprehensive study of the direct and indirect costs of adult asthma. J Allergy Clin Immunol 2003; 111: 1212-1218.

17 Szucs TD, Anderhub H, Rutishauser M. The economic burden of asthma: direct and indirect costs in Switzerland. Eur Respir J 1999; 13: 281-286.

18 Van Ganse E, Laforest L, Pietri G, et al. Persistent asthma: disease control, resource utilisation and direct costs. Eur Respir J 2002; 20: 260-267.

19 Hoskins G, McCowan C, Neville RG, Thomas GE, Smith B, Silverman S. Risk factors and costs associated with an asthma attack. Thorax 2000; 55: 19-24.

20 National Asthma Campaign Asthma Audit. The National Asthma Audit: assessing the burden of asthma. Asthma J 2001; 6: Suppl., 1-11.

21 Segal R, Ried LD, Mackowiak J. Cost of asthma illnesses: emergency department visits without admission. Pharm Pract Manag $Q$ 1995; 15: 72-82.

22 Barnes PJ, Jonsson B, Klim JB. The costs of asthma. Eur Respir J 1996; 9: 636-642.

23 Bateman ED, Boushey HA, Bousquet J, et al. Can guidelinedefined asthma control be achieved? The Gaining Optimal Asthma Control study. Am J Respir Crit Care Med 2004; 170: 836-844.

24 Balkrishnan R, Norwood GJ, Anderson A. Outcomes and cost benefits associated with the introduction of inhaled corticosteroid therapy in a Medicaid population of asthmatic patients. Clin Ther 1998; 20: 567-580.

25 Chan PW, Hussain S, Ghani NH, Debruyne JA, Liam CK. The direct cost of treating bronchial asthma in a teaching hospital in Malaysia. Southeast Asian J Trop Med Public Health 2002; 33: 600-603. 